\title{
Aplicación de teoría de juegos para la comprensión del Concepto y la función de la buena fe
}

Noé F. Piérola Castro

\section{Aspectos generales e introductorios}

Sobre la buena fe y otros conceptos a los que usualmente nos remiten muchas normas se han dado diversas opiniones que pretenden esclarecer su sentido, al no existir una determinación expresa de ellos en los textos legales.

Debido a nuestra experiencia lingüística, estamos tan imbuidos de estos conceptos que nos resultan "inmediatamente inteligibles" (De la Puente, 1993, T. II, p. 39), de modo tal, que al momento de contratar o de entablar algún tipo de relación jurídica parecería ser que entre las partes resulta de "conocimiento común" el contenido de dichos conceptos. Sin embargo, los problemas sobre lo que aparentemente es de "conocimiento común" se suscitan cuando en situaciones de conflicto o de incertidumbre jurídica los agentes involucrados interpretan cada cuál según su criterio, lo que en principio creían comprender del mismo modo.

En este sentido, el concepto de "buena fe" puede venir definido por los criterios que utilicen las propias partes (siempre y cuando opten por negociar) ${ }^{1}$, o el que utilice el heterocomponedor (tratándose de un

1 La aproximación entre las partes para lograr una autocomposición será factible si los costos de transacción son próximos a cero o irrelevantes comparados con los beneficios que provendrían del mantenimiento de la relación. Sin embargo es por lo general común que en este tipo de situaciones donde s encuentran involucrados factores personales y éticos (tales como conductas desleales o de mala fe) resulte poco probable lograr un acercamiento entre las partes para negociar, existiendo por lo contrario el riesgo que al menos una de las partes ya no esté dispuesta a mantener vigente ningún tipo de relación con la(s) otra(s). Como lo señala 
juez o árbitro) si optan por recurrir a él. En este último caso, se generan costos en la administración de justicia - si se recurre al Poder Judicial - o en la administración de contrato - si se recurre a un tercero dirimente, como un árbitro ${ }^{2}$, pudiendo dar origen a lo que en Teoría de Juegos se denominan como las demandas legales triviales (Rasmussen, 1996: pp. 121-130), si existen pocas probabilidades de ganar por la parte afectada, y factores emotivos influyen en la decisión de ir a juicio.

En esta misma disciplina, a los problemas que surgen cuando las

Rasmussen (1996: p. 128) una de las principales ideas equivocadas acerca de la teoría de juegos, así como de la economía en general es aquella que hace caso omiso de las motivaciones no racionales y de las no monetarias. "A menudo, las emociones son importantes en los juicios legales y los profesores de jurisprudencia les dicen a sus alumnos que cuando los casos que estudian parecen implicar disputas muy triviales para que valga la pena llevarlas a juicio, pueden adivinar que las verdaderas razones son emotivas".

2 Para los casos contractuales, recurrir al Poder Judicial o a un arbitro va a depender de lo que los teóricos en microeconomía (Kreps 1995: 671-672) han denominado las estructuras de gobierno de las transacciones, entendiendo por tales los modos que fijan las propias partes para la adecuación de la relación ante circunstancias que se presenten durante el desarrollo de la relación. Se dice que para la adopción de cada tipo de estructura de gobierno a determinada transacción, las partes tomarán en cuenta factores tales como la especificidad de los activos en juego, el grado de incertidumbre y la frecuencia de la transacción. Así, por ejemplo para un contrato denominado clásico, las propias partes fijan ex - ante lo que lo que se debe considerar como daño o como incumplimiento y atribuyen consecuencias a ellos. En este contrato se da una suerte de "autogobierno" de la relación, existiendo por tanto una menos discrecionalidad para atribuir o no la existencia de un daño o incumplimiento, y por lo tanto el incentivo para someter cualquier tipo de controversia al Poder Judicial (aunque en la práctica sabemos que esto va a depender mucho de las características del Poder Judicial ala cual nos sometamos). En los llamados contratos neoclásicos o de relaciones a tres bandas ya ano es el mismo contrato el que establece dichos supuestos y las respectivas consecuencias sino una tercera persona que las determinará de acuerdo al procedimiento que fijen las partes o al que se sometan. En estos casos, debido a su carácter más discrecional se recurre, a un tercero en el que confian las partes. Por último, existe un tercer tipo de contrato llamados de relación bilateral en los cuales, las partes "de una transacción no llegan a un acuerdo formal respecto a cómo ésta se adaptará a las circunstancias, sino que confían en su propia habilidad para resolverlas a medida que éstas van apareciendo". En estos casos, debido a que lo que está en juego son por lo general objetos de bastantes importancia para las partes, o lo que los economistas denominan activos bastante especificos, existe por lo general el incentivo para que las propias partes autorregulen su relación, o establezcan un gobierno unificado que reduzca cualquier incentivo al oportunismo. Para ello, se establece por ejemplo, obligación de entablar consultas bilaterales o inspecciones comunes a la ejecución de las obligaciones, recurso a mediadores o conciliadores, y por último, cuando existe demasiado en juego y la improbabilidad de detectar a tiempo una actuación oportunista o desleal en perjuicio de las otras partes es alta, se opta por la formalización de una persona jurídica. En los contratos de relación bilateral el elemento personal es demasiado fuerte pudiendo generarse en ellos aplicaciones de conductas de buena o mala fe. 
reglas de juego no son unívocas y permiten que un sujeto por decisión de un tercero o del alzar pueda obtener diferentes resultados por una misma conducta, se les denomina problemas de información imperfecta. Así por ejemplo, para Binmore, decir que un juego es de información perfecta o imperfecta es decir algo acerca de sus reglas (1994: 485). Un ejemplo probablemente nos puede ayudar a comprender mejor este concepto: Diremos que dos sujetos $\mathrm{X}$ e $\mathrm{Y}$ se han prestado mutuamente dos libros, y el sistema jurídico les ordena a cada cual, darle al libro prestado un trato semejante o recíproco del que recibe su propio libro en las manos del otro sujeto. Asumamos por tanto que existen dos posibilidades de acción: conservar el libro o descuidarlo. Entre ambos existe una distancia de 10 kilómetros y no existe ni teléfono, ni mucho menos correo electrónico para comunicarse; por lo tanto ni uno ni otro saben qué es lo que cada cual está haciendo con su libro. Esquemáticamente la relación se muestra de la siguiente manera:

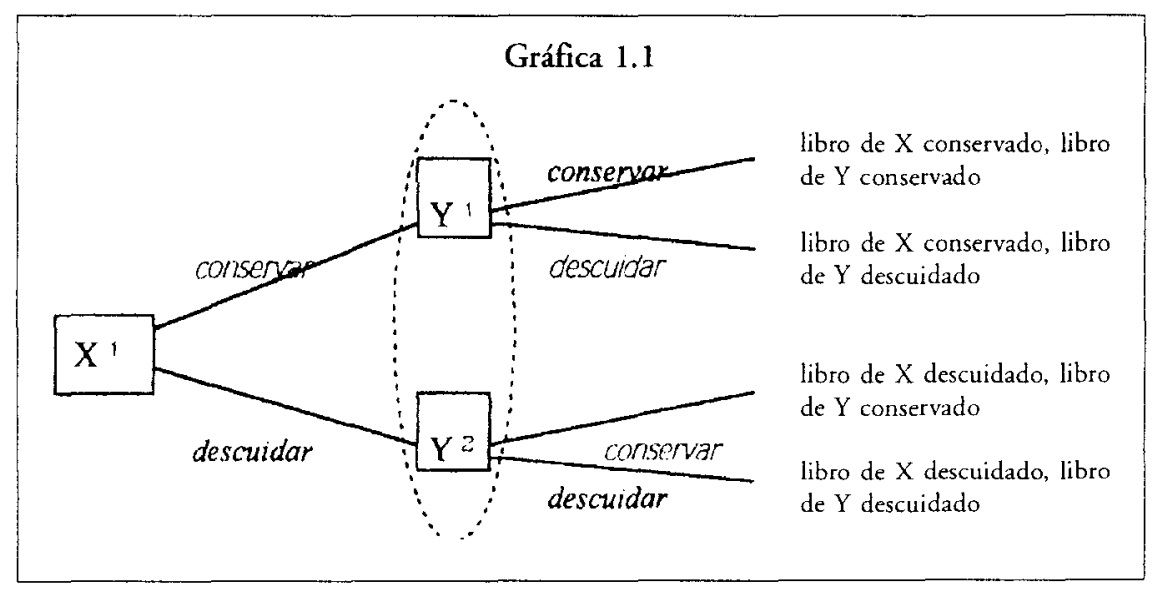

La interpretación es como sigue: asumimos que el sujeto $\mathrm{X}$ es el primero en tener contacto con el libro prestado y debe decidir entre conservarlo o descuidarlo. Este momento decisorio está representado por la casilla $\mathrm{X}^{1}$ en donde a la vez se muestran sus dos alternativas de acción. Luego de este movimiento, el sujeto $Y$, en forma recíproca al trato que le da el sujeto $\mathrm{X}$ a su libro, debe también optar por conservar o descuidar el libro ajeno.

El problema está en que $\mathrm{Y}$ no sabe si $\mathrm{X}$ ha optado por conservar o descuidar su libro; si lo vemos desde el punto de vista de Y, Y no sabe 
si se encuentra en la casilla $\mathrm{Y}^{1}$ o en la casilla $\mathrm{Y}^{2}$. Cuando un sujeto encuentra que no puede determinar en qué casillas del juego se encuentra, se dice que dicho sujeto tiene un problema de información imperfecta y que el conjunto de dichas casillas -también llamadas nodos- forman lo que se denomina en teoría de juegos conjuntos de información. Así, un juego se denomina de información perfecta si contiene para cada jugador, en cada conjunto de información, una sola casilla decisoria o nodo (Rasmussen, 1996: 63). Si Y está en $Y^{1}$ y conserva el libro ajeno, ambos sujetos saldrán ganando, o al menos, no perdiendo nada; si está en $\mathrm{Y}^{1}$ y decide no cuidar el libro ajeno, $\mathrm{Y}$ resultará beneficiado al final del juego en desmedro de $\mathrm{X}$, ya que conservará su libro en buen estado (gracias a las dedicaciones de $\mathrm{X}$ ) y habrá obtenido un tiempo adicional (el tiempo que no le dedicó al libro de $\mathrm{X}$ ) así como un ahorro de gastos de conservación, para emplearlos en otras actividades que seguramente le propinarían una mayor satisfacción que cuidar un libro ajeno. Este tipo de comportamiento es el típico comportamiento oportunista.

Por otra parte, si Y supiese que se encuentra en $Y^{2}$, optar por conservar el libro ajeno lo convertiría en un perdedor para esta relación, ya que invertiría de su tiempo, trabajo y dinero para cuidar un libro que a un momento determinado deberá devolver, para recibir a cambio su propio libro, probablemente en situación calamitosa. Recordemos que la regla no obliga a comportarse siempre en la forma más beneficiosa para la otra parte, sino tan sólo en forma recíproca como lo hace la otra parte. Así, si Y supiese que está en $\mathrm{Y}^{2}$ y opta por descuidar el libro ajeno, no se le podría recriminar por no conservar el libro ajeno; en este caso ambos sujetos saldrían perdiendo de esta relación.

De la misma forma sucede en el Derecho cuando una regla es de contenido amplio, como es el caso del concepto de la buena fe: Las partes no saben necesariamente como interpreta cada cual el concepto de buena fe y puede comportarse de un modo determinado que no sea el modo adecuado como lo entiende la otra parte. Un tercero, como un juez o árbitro, puede diferir por último de la interpretación que hacen las partes de dicho concepto. Al existir distintas formas de actuar de acuerdo a diversas interpretaciones se da un problema de información imperfecta en tanto las normas nos hacen referencias a criterios de buena fe sin que necesariamente se establezcan que tipo de acciones 
dichos criterios comprende. Sin embargo, una regulación extrema del concepto nos llevaría a sostener lo que decía Marguerite Yourcenar en Memorias de Adriano: "Tengo que confesar que creo poco en las leyes. $\mathrm{Si}$ son demasiado duras, se las transgrede. Si son demasiado complicadas, el ingenio humano encuentra fácilmente el modo de deslizarse entre las mallas de esa red tan frágil". (Citado en PUCP, 1994: 205). Por el momento dejamos el tema aquí, con el compromiso de retomarlo en el desarrollo del presente ensayo.

\section{La buena fe}

Los juristas son conscientes de la amplitud del concepto porque consideran que se trata de algo que trasciende el plano normativo. Así por ejemplo Ferreira señala que la buena fe

"es un elemento de la vida de relación humana que se ha incorporado al Derecho, pero que éste no lo ha reducido tal como es sino dándole precisiones técnicas, lo cual ha determinado que se convierta en un concepto jurídico" (1984: 80).

Este sentido de lo trascendental a lo legal algunos lo hallan como el fundamento de la buena fe y su ubicación en el plano moral:

"aflora en el hecho ético (...), y no es más que el acto o la acción, integrada con elementos internos y externos, cuya comprensión supone un recorrido que va desde las vivencias psicológicas del agente (...) pasando por la valoración concreta, hasta la proyección de esta última a través de principios hacia aquellos ideales puros, que son por así decirlo, verdaderos paradigmas del obrar humano, en su sentido puramente ideal" (Diccionario Omeba, 1976: 403-404).

Alsina Atienza señala que "en la buena fe reverdece una vez más el parentesco entre moral y derecho" (Citado por Diccionario Omeba, 1967: 404). Ripert por último, también coincide en la vinculación entre la buena fe y la moral, al señalar que, 
"la buena fe es uno de los medios utilizados por el legislador y los tribunales para hacer penetrar la regla moral en el derecho positivo" (Citado por Ghestin, 1988: 203).

Siendo esta la orientación del campo en el cual se debe mover la buena fe según los estudiosos del Derecho, De la Puente realiza una recolección de los diversos significados que varios tratadistas otorgan a la buena fe, siempre ligándola a la moral (1993: T.II, 24).

Así, para Bonfante, la buena fe es la "Ausencia de dolo o mala fe". Para Windscheid, la buena fe es la "honesta convicción".

Para Tuhr, la buena fe es "la honradez".

Para Gorphe, la buena fe es "voluntad sincera, leal y fiel".

Para Ghestin, la buena fe es "sinceridad y lealtad".

Para Cornu, la buena fe es el "deber de asistencia, de colaboración, de cooperación, de ayuda mutua y, al límite, de amistad y de fraternidad".

Para Miccio la buena fe es "la ausencia de fines ulteriores a la contraparte y que le son dañinos".

Para Planiol y Ripert, la buena fe es "la obligación de obrar como hombre honrado y consciente".

Como lo ha señalado el mismo De la Puente, al tratarse de un tema que se ha incorporado en el Derecho, resultaría más útil comprender la buena fe partiendo de la forma cómo ha sido este concepto legislado (Op. cit.: 25). Así volvemos al criterio de los juristas los cuáles entienden que existen dos criterios de buena fe en forma legislativa: la llamada buena fe objetiva (o buena fe lealtad), y la llamada buena fe subjetiva (también llamada buena fe creencia).

Se entiende que nos encontramos ante la buena fe objetiva cuando la misma norma establece la forma como se debe realizar una conducta: con lealtad, honestidad, etcétera. Mientras que nos encontramos ante la buena fe creencia cuando la norma constata una situación de falta de información o conocimiento que amerita que el ordenamiento atribuya ciertos derechos a determinados comportamientos.

Existen dos criterios respecto a la unitariedad de ambas buena fe. Juristas como Ferreira, sostienen que la buena fe es un concepto unitario, y que ambas manifestaciones se integran en una sola. Otros, como De la Puente, consideran que en el fondo se tratan de conceptos dis- 
tintos que por "imperativos de moral se unifican bajo un mismo concepto".

En uno u otro sentido, no llegamos al sustrato de la buena fe. En un caso se nos señala que las dos manifestaciones forman un concepto único, sin hacerse mención del común denominador de ambos; por otra parte en el otro caso, se niega el posible origen conceptual de ambos tipos de buena $\mathrm{fe}$, sin haber indagado el sustrato de ambos conceptos.

A nuestro criterio si bien es interesante desde un punto netamente académico tratar de esclarecer si nos hayamos o no ante una unidad conceptual, debemos buscar más allá de ello cuál es la función que cumple la buena fe en la estructuración de lo que conocemos como Derecho Civil Patrimonial, y en general del marco legal en el que se desenvuelve una economía de mercado, en la que hoy estamos inmersos, para de allí buscar si se justifica funcionalmente el mantenimiento de la unidad. Para ello nos permitimos intentar esquematizar conceptualmente ambas formas de buena fe tomando los casos más característicos.

\section{Las concepciones clásicas de buena fe objetiva y subjetiva}

Partiremos de la definición doctrinaria que se le otorga a ambas y aplicaremos dichas definiciones a una situación estratégica concreta extraída de la ley.

\subsection{La buena fe objetiva}

Para Messineo (1986: 206), la "observancia de la buena fe objetiva (lealtad) por parte de los contratantes (acreedor y deudor) significa que el acreedor no debe pretender más, en el ejercicio de su crédito, ni el deudor puede rehusarse a dar menos, en el cumplimiento de su obligación, de lo que exige el sentido de probidad, habida cuenta de la finalidad del contrato".

Por su parte Puig Brutau (1981: 415) señala que en el caso de la buena fe objetiva "se trata de un criterio de valoración objetiva para juzgar si una conducta alcanza el nivel exigible. Es un criterio de valoración, un standard o prototipo de conducta, fundado en las reglas 
objetivas que tipifican la honradez en el comercio o en las relaciones sociales".

Por último, Diez Picazo considera en relación a la buena fe objetiva que "la buena fe es lo que se ha llamado un standard jurídico, es decir, un modelo de conducta social o, si se prefiere, una conducta socialmente considerada como arquetipo, o también una conducta que la conciencia social exige conforme a un imperativo ético dado".

De la Puente sintetiza las características que la doctrina otorga a la buena fe objetiva; así señala que:

a) Se trata de un deber de conducta impuesto al sujeto, con un contenido eminentemente ético.

b) Este deber de conducta importa que no se perjudique los intereses ajenos fuera de los límites impuestos por la tutela legítima de los intereses propios.

c) Para apreciar la conducta se prescinde del punto de vista subjetivo de las partes para referirse a un criterio objetivo.

d) Esta objetividad no excluye sin embargo que dejen de tomarse en consideración un elemento subjetivo, como es el dolo o culpa del sujeto. Quien actúa con dolo o culpa no puede escudarse en la buena fe objetiva.

e) El criterio objetivo consiste en la comparación de la conducta del sujeto con un standard jurídico, o sea un prototipo de conducta social media.

f) El standard jurídico aplicable debe buscarse teniendo en cuenta el contexto social en el que actúa el sujeto".

\subsection{La buena fe creencia}

Como nuestro propósito es más que todo la formulación estratégica de un comportamiento de buena fe, para lo que comprendemos por buena fe creencia, citaremos lo que De la Puente señala, en síntesis, qué debe entenderse por buena fe subjetiva:

a) "Se trata de una creencia personal del sujeto respecto de que su actuación es conforme a Derecho, o sea que tiene un contenido ético.

b) Esta creencia pese a ser subjetiva, no es candorosa sino razonada, 
en el sentido que el sujeto ha apreciado los elementos de juicio que estaban a su disposición.

c) La apreciación del sujeto es fruto de su diligencia, esto es que ha hecho una búsqueda razonable de los elementos de juicio.

d) En este proceso de formación de la creencia no ha actuado con dolo o culpa.

e) La creencia del sujeto puede recaer tanto en su propia situación como en la de la persona con la cual se relaciona.

f) La creencia, así formada, determina la conducta del sujeto, en el sentido que hay una absoluta correspondencia entre su creer y su actuar.

g) El Derecho da un tratamiento favorable a la conducta del sujeto por razón de su creencia" De la Puente (1993: TII: 30).

\section{La formulación estratégica}

Una norma que podemos tomar como ejemplo para esquematizar el contenido al que se hace mención con la buena fe objetiva, es el artículo 1362 del Código Civil que a la letra dice:

"Los contratos deben negociarse, celebrarse y ejecutarse según las reglas de la buena fe y común intención de las partes".

Tomaremos el caso de la ejecución de un contrato para esquematizar cómo se daría una relación con el contenido de la buena fe. Para avanzar sobre lo ya recorrido, imaginemos que en nuestro ejemplo anterior, el deber de otorgarle al libro ajeno un trato semejante o recíproco al que está recibiendo el libro propio en manos ajenas, no está impuesto en norma positiva alguna, sino que es una obligación que se desprende de un contrato firmado entre $\mathrm{X}$ e Y. Según la regla contenida en el artículo $1362^{\circ}$, la ejecución de este contrato se debe realizar de buena fe, y según la doctrina, aplicando el criterio de buena fe objetiva. En este caso, nuestra formalización estratégica ${ }^{3}$ es la misma que vimos

3 En rigor, este tipo de formalización es la que se conoce en Teoría de Juegos como Formalización Extensiva, ya que por Formalización Estratégica se entiende la formalización mediante cuadros de pagos. Ver Binmore (1994: 31). 
en el gráfico 1.1., sin embargo ahora traduciremos el resultado en términos de utilidad para cada uno de los sujetos a través del par ordenado $(x, y)$ en el que $x$ representa la utilidad de X e $y$ la de Y, otorgándoles unos valores tentativos.

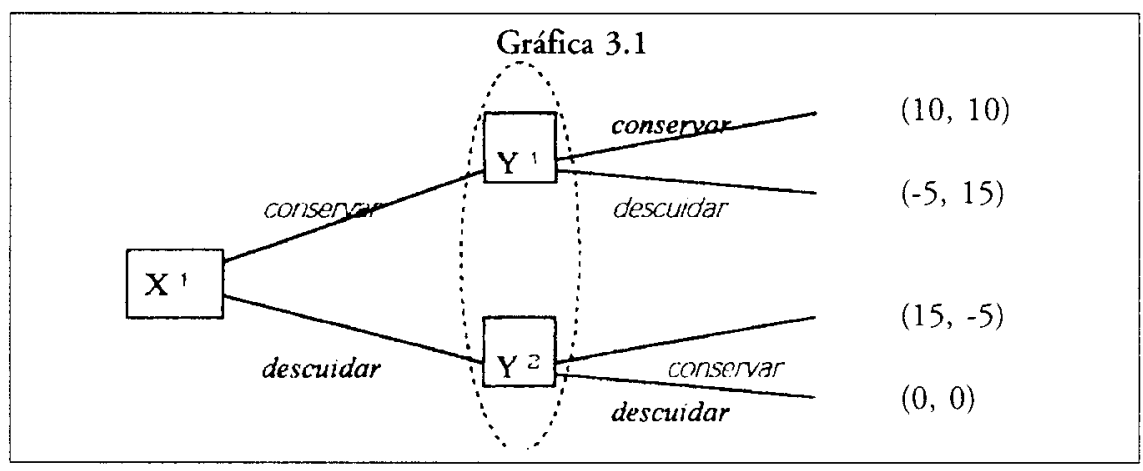

- Si ambos conservan los libros recíprocamente ajenos, obtendrán cada uno una utilidad de 10.

- Si X conserva el libro de Y, pero Y descuida el libro de X, X no obtiene ninguna utilidad, y por el contrario pierde los recursos que empleó en el cuidado del libro de Y, por lo que su utilidad es de -5; $Y$ por su parte sale beneficiado con el cuidado de su libro, y adicionalmente con una disponibilidad de recursos para emplearlos en otra actividad siendo así su utilidad de 15 .

- Las mismas consecuencias acontecen si $\mathrm{X}$ actúa descuidando el libro de $\mathrm{Y}$ y $\mathrm{Y}$ conservando el libro de $\mathrm{X}$, sino que el valor de los pagos cambian de orden en el par ordenado $(x, y)$.

- Por último, si ninguno coopera en la conservación del libro ajeno, ninguno obtiene utilidad alguna del contrato, siendo lo mismo a no haber contratado. En este caso el contrato habría sido ineficiente y sólo habría significado para las partes costos de transacción sin justificación.

El problema está como lo mencionamos en el primer ejemplo, en que ambos sujetos no saben cómo está actuando el otro, y en tal sentido cada uno tiene que decidir de acuerdo al conocimiento que tienen sobre el otro y la creencia de cómo éste va a proceder. Hemos indicado que la línea punteada engloba el conjunto de información del sujeto $Y$. Esto significa que $Y$ no sabe si se encuentra en $Y^{1}$ o $Y^{2}$. A pesar de este problema de información la doctrina entiende que la buena fe objetiva 
les impone un deber de actuar en forma leal. ¿Pero, qué se puede entender por lealtad?

\subsection{Los costos de información y la buena fe creencia}

Como ya lo mencionamos con anterioridad, la doctrina tiende a manifestar que el deber de actuar de buena fe implica un standard de diligencia en el sentido que no se le puede exigir a nadie un comportamiento por encima del que correspondería "con la conducta social media" teniendo en cuenta el contexto social en el que actúa el sujeto (De la Puente, 1993: 34).

Para nosotros, si existe un deber de actuar de buena fe, o de actuación en forma leal, este deber no puede ser entendido sin considerar el estado de creencia del cual partirá cualquier tipo de decisión del sujeto; y cuando nos referimos a un estado de conocimiento debemos estar hablando de un standard de él, en el sentido que no todo conocimiento es útil. Si hablamos de standard, nos estamos refiriendo a un término "que hace alusión al «sentido común", a las concepciones y conductas del trafico "normal" (Esser, en De los Mozos, 1965: 123).

La fijación del standard va a venir dado por un análisis costo-beneficio en dos tipos de sujetos decisores: las partes, y el sistema jurídico. Pero debe notarse que es un standard que versa sobre el conocimiento que puede adquirir el sujeto, es decir, sobre su aspecto subjetivo. Comenzando por este último, la doctrina entiende, a nuestro juicio con muy buen criterio, que no se le puede imponer una actuación excesivamente onerosa para las partes. Así por ejemplo, el mismo ordenamiento en el artículo $1426^{\circ}$ del Código Civil reconoce la posibilidad de que una parte no cumpla del modo previsto en el título:

"En los contratos con prestaciones recíprocas en que éstas deben cumplirse simultáneamente, cada parte tiene derecho de suspender el cumplimiento de la prestación a su cargo, hasta que se satisfaga la contraprestación o se garantice su cumplimiento".

Del mismo modo, existen remedios contractuales como la resolución contractual, o la tradicional cláusula rebus sic stantibus, que posibilitan a las partes no actuar como contractualmente probablemente estaba previsto. 
Por otra parte, si la conducta de un agente resulta negligente, no consideramos que el sistema debe brindarle la protección que le hubiese correspondido de haber actuado de buena fe. El sistema por tanto impone un mínimo de costo en la ejecución de toda prestación que se deba realizar de buena fe. En tal sentido aprovechando el citado artículo $1426^{\circ}$, una parte no podría exigir el cumplimiento de la otra basándose en que esta debía actuar de buena fe. El mismo sistema tácitamente impone los límites.

El problema surge en la determinación del término medio; a nuestro criterio si bien el propio sistema no lo define, es por la imposibilidad de fijar esquemáticamente una fórmula aplicable a todos los casos. Creemos que dicha definición la deja al criterio de razón de los sujetos intervinientes. $Y$ es aquí cuando analizamos el costo-beneficio que significa para dichos sujetos incurrir en el deber de diligencia que impone la buena fe. Los costos de información deben ser menores al beneficio que otorgue contar con dicha información, el cual en otros términos es saber en la posición exacta en la que estratégicamente uno se encuentra.

\section{Costos Información < Beneficio de saber mi ubicación estratégica}

El deber de diligencia exigido consiste por tanto en un tema de costos de información razonables, y el estado de buena fe subjetiva va a depender de él.

\subsection{La obligación de actuar de buena fe}

Hemos visto que el llamado aspecto subjetivo de la buena fe se remite a un problema de costos de información razonables, sin embargo aún subsiste el tema de lo que se entiende por buen fe objetiva. Se dice que nos hallamos ante un deber de actuar lealmente. Nosotros creemos que si bien es cierto existe una obligación de actuar de buena fe, no nos encontramos en estricto ante un concepto desvinculado al de buena fe subjetiva, sino que por el contrario se trata de una consecuencia de encontrarse en un problema de conocimiento determinado habiéndose dispuesto de los recursos razonables. La obligación en sí busca evitar conductas oportunistas, e impone sanción a quien seca partido 
de la buena fe subjetiva en que se encuentra la otra parte, a pesar de haber incurrido en los costos de información razonables.

\section{A manera de conclusión}

Si bien consideramos que el tema de la buena fe da para mucho más, su estudio no puede estar referido en un único plano, en el plano de la ética o moral.

A pesar de la simpleza del esquema mostrado, creemos que detrás del principio de buena fe así como otros conceptos a los cuales comúnmente se remiten las normas positivas existe, aparte de la valoración ético-moral, una valoración económica, o si se desea llegar más al trasfondo, una valoración de la Política (con mayúscula) que al menos formalmente persigue una sociedad determinada. A nuestro juicio, resulta claro, que lo que se persigue con mecanismos como la buena fe, es fomentar conductas cooperativas por parte de los sujetos, dejando de lado cualquier tipo de oportunismo, a no ser que la opción cooperativa exceda la racionalidad individual - situación para la cual el Derecho establece también mecanismos como la excesiva onerosidad de la prestación, la cláusula revus sic stantibus, o si lo queremos ver fuera del contexto civil patrimonial, la separación de cuerpos y el divorcio.

El problema surge porque los sujetos del Derecho no son entes completamente racionales -en sentido económico- que pueden prever todas las posibles contingencias cuando surge una relación. Muy por el contrario, la realidad siempre nos hace constatar que nuestra racionalidad es limitada, y que en tal sentido siempre estaremos expuestos a conductas oportunistas de los posibles sujetos que entren en algún tipo de relación con nosotros. Si el Derecho no tuviese un fin social, probablemente bastaría establecer las pautas mínimas para los intercambios, y si cada cual tiene problemas de información debido a nuestra inherente racionalidad limitada, será problema de adaptación, o en términos evolutivos, de selección natural. Si bien el sistema permite esta opción para supuestos en que no existe nada mejor que la decisión individual para determinar el rumbo de la vida y actividades de los sujetos, no la permite en forma absoluta de modo tal que no sean 
posibles porque siempre van a existir sujetos adversos al riesgo que a pesar de que pueden lograr beneficios mediante intercambios determinados, van a inhibirse de optar por esquemas cooperativos tales como la contratación, la formación de personas jurídicas o, por que no decirlo, el matrimonio, debido a que tienen el temor de que otro sujeto con una mayor racionalidad va a sacar un mayor beneficio de estas vinculaciones colocándolos en una situación inferior a como iniciaron.

Así, conceptos como la buena fe, las buenas costumbres, el orden público, son a nuestro criterio conceptos cooperativos, que buscan reducir costos de transacción o intercambio (en sentido no sólo económico), en el aspecto de costos de información. En el tema de la buena $\mathrm{fe}$, lo que se busca proteger es la racionalidad limitada de los agentes, debido a que no resulta razonable -haciendo un análisis costo-beneficio- que incurran en excesivos costos de información para saber si otros agentes están actuando, o han actuado, frente a ellos en forma oportunista (caso por ejemplo del que adquiere por prescripción, poseyendo de buena fe).

Se trata a nuestro juicio de un mismo concepto que engloba a la vertiente subjetiva y objetiva, e impone una protección legal a quien razonablemente, ante determinadas circunstancias fácticas o documentales, ha actuado conforme al conocimiento que razonablemente ha obtenido de acuerdo a las circunstancias de los otros sujetos o de los hechos materiales, imponiendo un deber a los otros sujetos de actuar sin aprovecharse del conocimiento del cual dispone la otra parte.

Creemos que el propósito de la buena fe es desde un punto de vista netamente económico, brindar credibilidad en el sistema, más aún tratándose de un esquema de economía de mercado, para el cual sólo mediante los intercambios realizados por propia decisión de los particulares, se llega a la situación de eficiencia óptima. Si no se estableciesen mecanismos como la buena fe, las transacciones se encarecerían o en el peor de los casos no se realizarían, y los recursos no fluirían hacia sus usos más eficientes.

Con respecto a la aplicación de Teoría de Juegos confiamos en que su aplicación sea a futuro una herramienta útil para el análisis estratégico de conductas. Todos los conceptos de cooperación, competición, información y decisión, se derivan de ella, pero en ella se hayan formulados matemáticamente, siendo su espectro más amplio que el del análisis económico. 


\section{Bibliografía}

De Los Mozos, José Luis.

1965 El principio de buena fe. Barcelona: Bosch.

Puig Brutau, José.

1981 Introducción al Derecho Civil. Barcelona: Bosch.

Ferreira, Delia.

1984 La buena fe. Madrid: Montecorvo S.A.

Messineo, Francesco.

1986 Doctrina general del contrato. Buenos Aires: Ediciones Jurídicas Europa-América, T.I.

De la Puente, Manuel.

1993 El Contrato en General. Lima: Fondo Editorial de la Pontificia Universidad Católica del Perú, Biblioteca Para Leer el Código Civil, Vol. XI, T. II.

KREPS, David.

1995 Curso de Teoría Microeconómica. Madrid: Mc Graw: Hill, $754 \mathrm{p}$.

RASMUSEN, Eric.

1996 Juegos e información: una introducción a la teoría de los juegos. México: Fondo de Cultura Económica, 548 p.

GHESTIN, Jacques.

1998 Le contrat: Formation. París: L.G.D.J.

BINMORE, Ken.

1994 Teoría de Juegos. Madrid: Mc Graw Hill. 